\title{
социология
}

DOI 10.17805/ggz.2017.4.7

\section{Оценка выпускниками московских вузов социально-гуманитарного профиля своего образования и перспектив трудоустройства}

\author{
Д. А. ТИХОМИРОВ, Е. В. СИДНЕВА
}

РОССИЙСКИЙ ЭКОНОМИЧЕСКИЙ УНИВЕРСИТЕТ ИМ. Г. В. ПЛЕХАНОВА

В данной статье анализируются мнения выпускников московских вузов 2014-2016 гг. относительно полученного ими образования и его роли в трудоустройстве на основе результатов авторского социологического исследования. Проблема трудоустройства выпускников вузов социально-гуманитарного профиля раскрывается как важная социогуманитарная характеристика российского общества.

Ключевые слова: высшее образование, выпускники вузов, проблемы трудоустройства

\section{Education and Employment Prospects: Evaluation by Graduates of Moscow Universities for Social Sciences and Humanities \\ D. A. TIKHOMIROV, E. V. SIDNEVA \\ Plekhanov Russian University of Economics}

This article analyzes opinions of graduates of Moscow universities in 2014-2016 regarding their education and its role in employment based on the results of the authors' sociological research. The problem of employment of graduates of higher educational institutions for social sciences and humanities is revealed as an important socio-humanitarian characteristic of Russian society.

Keywords: higher education; graduates of universities; problems of employment

В аспекте экологии культуры представляется значительной проблема трудоустройства выпускников вузов социально-гуманитарного профиля. Поскольку речь идет о носителях профессионального знания, понимания и умения (термин И. М. Ильинского - Ильинский, 2016) применительно к различным сторонам культуры, ее несущим конструкциям (Кузнецова, 2012; Ауков, Ауков Вл., 2008, 2013, 2014), трудоустройство таких лиц, получивших соответствующее высшее образование, становится важной социогуманитарной характеристикой российского общества, как и общества определенного цивилизационного типа вообще.

Система высшего образования в России функционирует не достаточно эффективно, это, в частности, относится к недостаточной продуманности содержания, к несформировавшейся гуманитаризации высшего образования (Кузнецова, 1990: Ильин- 
ский, 2002; Плаксий, 2014; Аиалог..., 2010). Это касается как качества подготовки выпускников, так и серьезного дисбаланса по определенным направлениям подготовки (перепроизводство юристов, экономистов, менеджеров и дефицит инженеров и других технических специалистов), что значительно осложняет трудоустройство выпускников вузов социально-гуманитарного профиля, особенно по специальности (хотя с точки зрения законодательства, корректнее говорить «направление подготовки»). Исследование трудоустройства выпускников в России, проведенное в 2014 г. Минобрнауки совместно с Пенсионным фондом, показало, что средняя доля трудоустройства выпускников составляет $75 \%$ (Ивойлова, 2015), а 25\% не могут найти работу и спустя год после получения диплома (Каждый..., 2015: Электронный ресурс). Среди всех выпускников, не нашедших работу в течение первого года после окончания вуза, $32 \%$ экономисты и $18 \%$ юристы (Ивойлова, 2015). Иная ситуация сложилась в области инженерии, особенно высокотехнологичной, где доля трудоустроенных выпускников достигает 95-100\% (Минобрнауки..., 2015: Электронный ресурс).

Проблемы образования и трудоустройства выпускников вузов не обделены вниманием исследователей и являются достаточно хорошо изученными. Только в Москве, не говоря уже о других регионах страны, есть несколько исследовательских центров, занимающихся изучением этой проблематики (например, Высшая школа экономики, РАН, Московский гуманитарный университет (Ильинский, Ауков, 2005; Ауков, Гневашева, 2009; и др.). Вместе с тем постоянные перемены в системе высшего образования и высокая неопределенность социальной среды, усиливающаяся экономическим кризисом и все чаще появляющимися прогнозами об исчезновении в недалеком будущем целого ряда профессий, определяют актуальность исследования восприятия выпускниками вузов образовательного процесса в контексте их трудоустройства.

В этой связи целью данной статьи стало выявление мнения выпускников вузов социально-гуманитарного профиля о полученном ими образовании и его роли в их трудоустройстве. Именно для этих выпускников, как мы показали выше, проблема трудоустройства стоит наиболее остро. Объектом социологического исследования выступили выпускники социально-гуманитарного профиля подготовки московских высших учебных заведений (РЭУ им. Г. В. Плеханова, РАНХиГС, РГГУ, РУАН и др.), получившие первое высшее образование в период 2014-2016 гг. В качестве основного метода исследования был использован авторский анкетный опрос $(\mathrm{N}=300$, выборка целевая, полученная с помощью метода снежного кома), проведенный в начале 2017 г. Было опрошено в среднем по $12 \%$ выпускников таких востребованных направлений подготовки, как государственное и муниципальное управление, менеджмент, маркетинг, международные отношения, юриспруденция, реклама и связи с общественностью, социология, политология. Среди опрошенных выпускников, $76 \%$ работают (45\% работают не по специальности, $28 \%$ - по специальности, $3 \%$ открыли свое дело), а $24 \%$ не работают.

Рассмотрим основные результаты исследования.

Выпускники демонстрируют высокую степень неудовлетворенности полученным образованием. Распределение ответов на вопрос «Если бы у Вас была возможность вернуться в прошлое и вновь выбрать направленность профессиональной подготовки и вуз, какой выбор Вы бы сделали?» показало, что только треть (34\%) выпускников сделали бы тот же выбор, 11\% выбрали бы то же направление подготовки, но другой вуз, $17 \%$ выбрали бы тот же вуз, но другое направление подготовки, а 27\% сделали бы совсем иной выбор вуза и направления подготовки. Аругими словами, вузом остались 
довольны только $51 \%$ выпускников, а специальностью - $45 \%$, не довольны вузом $38 \%$, а специальностью - $44 \%$. Больше всего удовлетворены полученной специальностью и выбранным вузом выпускники направлений «государственное и муниципальное управление» - 59\% и «менеджмент» - 52\%, меньше всего - выпускники направлений «социология» $-8 \%$ и «реклама и связи с общественностью» $-20 \%$, большинство которых (52\% и 60\%), если бы они могли вновь выбрать вуз и специальность, предпочли бы другой вуз и специальность. Очевидно, что причины подобных оценок кроются не только в проблеме профессиональной ориентации (см. рис. 1), которая высвечивает низкую социальную субъектность молодого поколения (Алиев, 2015), но и качество образования в столичных вузах (Тихомиров, 2016), что отражается на трудоустройстве их выпускников.

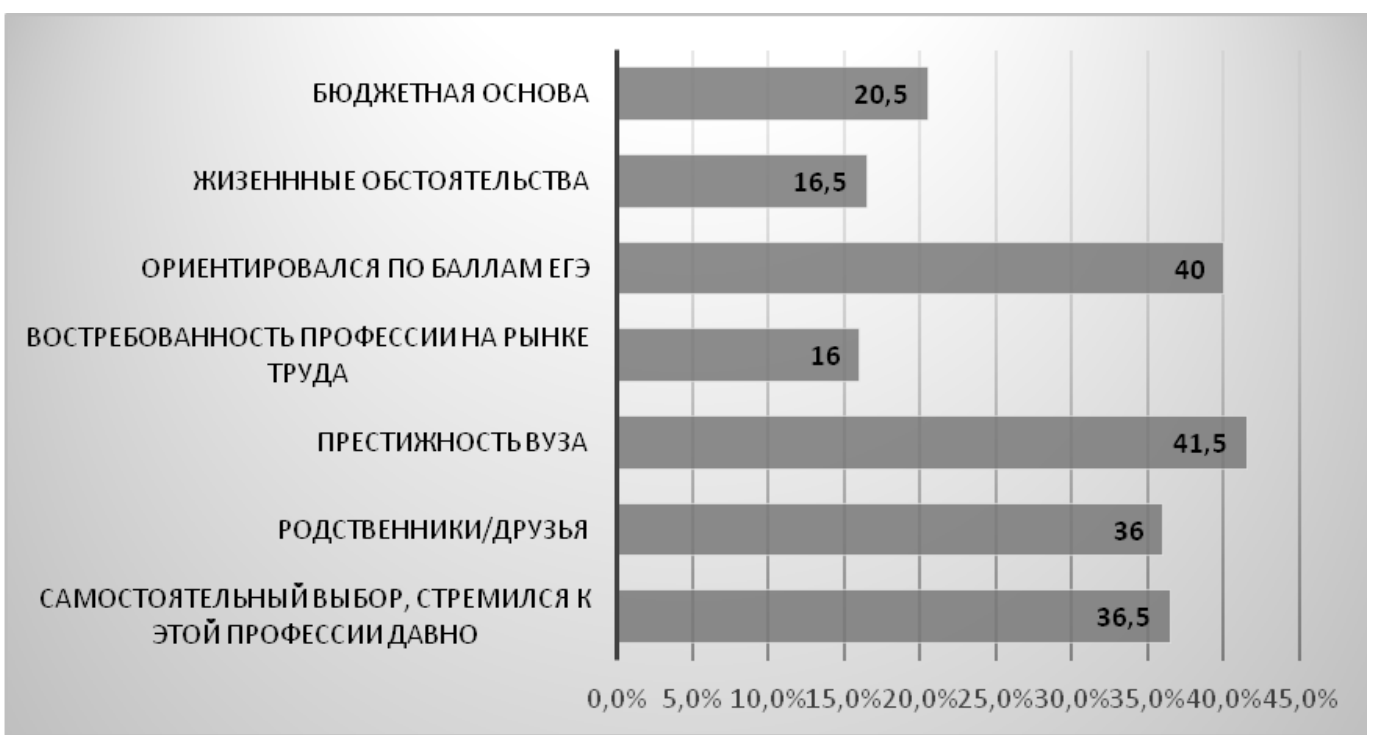

Рисунок 1. Основные мотивы выбора направления подготовки выпускниками вузов, в \%

Серьезные нарекания возникают у выпускников вузов к качеству полученного образования, особенно к практической его составляющей. Уровнем общей подготовки по выбранному направлению (теоретические знания и прикладные навыки для работы по специальности) удовлетворены $58,5 \%$ опрошенных (из них полностью удовлетворены только 16,5\%), а не удовлетворены - 41,5\% (из них полностью не удовлетворены - 4\%). Владением базовым набором компьютерных программ (Word, Excel, PowerPoint и др.) удовлетворены только $30 \%$ выпускников (из них 22,5\% полностью удовлетворены), не удовлетворены - $48 \%$ (из них, $17 \%$ полностью не удовлетворены). Аостаточную подготовку по использованию необходимых по специальности компьютерных программ получили лишь $31,5 \%$ опрошенных выпускников, $37 \%$ она кажется не достаточной, а $31,5 \%$ отмечают практически полное отсутствие знаний в этой области. Но наибольшее недовольство выпускников связано с преподаванием иностранных языков в вузе. Большинство (62,5\%) респондентов остались недовольны уровнем обучения иностранным языкам, противоположной позиции придерживаются только $11 \%$ опрошенных. 
Вопрос о соответствии профессиональной подготовки выпускников требованиям рынка труда высветил серьезную озабоченность молодых людей по этому поводу. Большая часть опрошенных (40\%) отметили, что их профессиональная подготовка лишь частично соответствует потребностям рынка труда, $25 \%$ полагают, что скорее соответствует, а $8 \%$ полностью уверены в этом, тогда как $21 \%$ придерживаются мнения о несоответствии полученной профессиональной подготовки требованиям современного рынка труда. Причем понимание молодыми людьми пробелов их профессиональной подготовки приходит уже во время обучения в вузе (большинство опрошенных имели опыт работы в студенческие годы), которые они пытаются устранить, посещая дополнительные образовательные программы (почти $42 \%$ респондентов обучались на языковых и компьютерных курсах).

Результаты исследования еще раз продемонстрировали остроту проблемы трудоустройства выпускников вузов социально-гуманитарного профиля. Напомним, что среди опрошенных выпускников, $76 \%$ работали, а 24\% так и не смогли найти подходящую работу. Причин этого множество, но в данном случае мы акцентируем внимание на тех из них, которые касаются работы вузов как по профессиональной подготовке студентов, так и по оказанию им содействия в трудоустройстве. Большинство $(57 \%)$ респондентов далеко не всегда были информированы о проводимых в вузе мероприятиях, содействующих трудоустройству (ярмарки вакансий, дни карьеры и др.), треть $(34 \%)$ выпускников отметили, что они были достаточно информированы, а 9\% вообще не слышали о подобных мероприятиях в их вузе. Аля улучшения оповещения студентов о таких мероприятиях стоит использовать дополнительные каналы коммуникации, включая интернет и социальные сети. Но, главным образом, необходимо повышать их эффективность, которая пока остается чрезвычайно низкой. Так, участие в них принимали 40\% студентов, а полезны они оказались лишь для $5 \%$ (нашли себе там стажировку, подработку, работу). Половина (51\%) респондентов отметили, что вуз предоставлял им место прохождения производственной практики по специальности, однако только $6 \%$ устроились на работу в организацию, в которой проходили практику.

Работодатели пока слабо взаимодействуют с вузами не только по подготовке кадров, но и по рекрутированию студентов. Только $13 \%$ выпускников вузов были замечены и приглашены на работу самими работодателями. Большая часть (39\%) опрошенных нашли работу при помощи родственников или друзей, 30\% по объявлению (на сайте вакансий или работодателя).

Большинство выпускников столкнулись с различными трудностями при поиске работы (лишь 15\% не испытали никаких трудностей), основными из которых являлись: отсутствие опыта $-38 \%$, низкая заработная плата $-26 \%$, отсутствие необходимых знаний и навыков по специальности - $25 \%$, отсутствие дополнительных навыков (знание иностранных языков, компьютерных программ) - 18\%, небольшое количество вакансий по выбранной специальности $-17 \%$, отсутствие связей $11 \%$. Итак, в процессе поиска работы перед выпускниками возникает непростая дилемма: либо мало платят (а уровень заработной платы является основным фактором выбора работы, см. рис. 2, с. 54), либо мало опыта и знаний. Отсутствие опыта работы остается ключевым препятствием трудоустройства выпускников, даже несмотря на то, что большинство из них стараются работать во время обучения в вузе (по результатам опроса, $70 \%$ респондентов на момент окончания вуза уже имели опыт работы: $28 \%$ по специальности, а $42 \%$ не по специальности). 


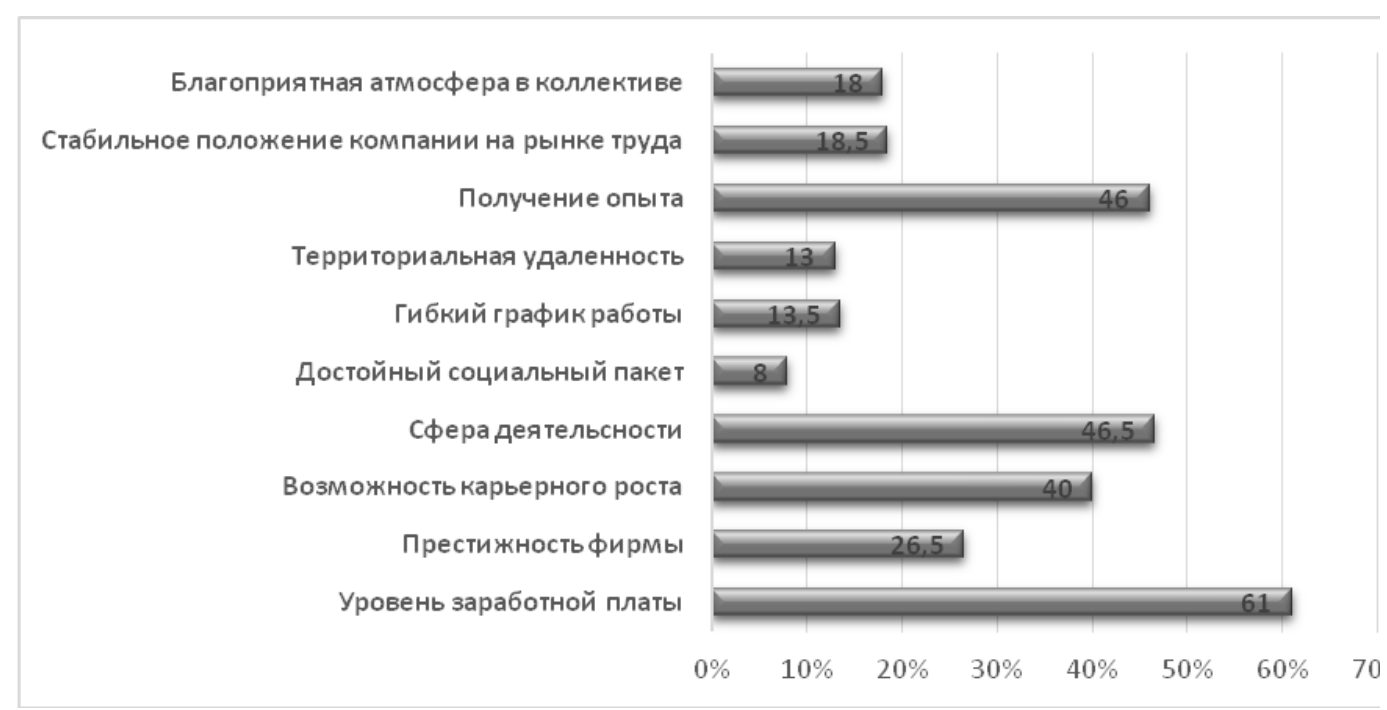

Рисунок 2. Основные факторы при выьборе работы выпускниками, в \%

Выбор работы, исходя из чисто материальных соображений, не всегда является лучшим вариантом, что и отражается на удовлетворенности работой. Полностью удовлетворены нынешним местом работы только 35\% опрошенных выпускников вузов, $37 \%$ скорее удовлетворены, но при возможности сменили бы его, а 20\% не удовлетворены своим местом работы.

Таким образом, проблема трудоустройства выпускников вузов социально-гуманитарного профиля подготовки, особенно по специальности, стоит остро. А ею преимущественно в среде выпускников определяется отношение к вузу и полученной специальности. Выпускники демонстрируют высокую неудовлетворенность качеством полученного образования, прежде всего слабо выраженной практической составляющей, а также навыками пользования специальными компьютерными программами и владения иностранным языком, что воспринимается ими как важный фактор, препятствующий успешному трудоустройству. Это приводит к тому, что пробелы профессиональной компетенции студенты вынуждены устранять на платных образовательных курсах. Тем не менее, это не решает проблему трудоустройства, которая сводится выпускниками к отсутствию достаточного опыта, знаний и приемлемых материальных условий. Серьезные вопросы возникают и к работе вузов по помощи в построении карьеры (включая и содействие трудоустройству) студентов и выпускников, поскольку их деятельность в этом направлении, как правило, является неэффективной. Это определяет необходимость активного взаимодействия вузов и работодателей, особенно при формировании и реализации учебных программ, увеличивая тем самым прикладную составляющую обучения на базе конкретных организаций, предоставляя возможность студентам освоения и закрепления знаний на практике.

Не представляется возможным обеспечивать требования и ожидания экологии культуры, когда не решается проблема трудоустройства выпускников вузов социогуманитарного профиля. Можно сказать, что это взаимосвязанные проблемы, 
и чем более определенным становится такого рода трудоустройство, тем выше достигаемый уровень әкологии культуры. Культура не может быть сведена к шедеврам искусства, в своей основной части это характеристика современного общества, его повседневности. В ведущих чертах именно повседневность характеризует накопленный обществом человеческий потенциал (Ауков, Аапшин, 2010), а его (потенциала) качество не являет себя непосредственно, часто представляет собой трудно формализуемую задачу. Одним из признаков его действительного накопления и определения культурной картины мира, приоритетной в данном обществе, становится измеримый показатель трудоустройства выпускников вузов социогуманитарного профиля.

\section{СПИСОК АИТЕРАТУРЫ}

Алиев, В. В. (2015) Основы исследования социальной субъектности молодежи // Знание. Понимание. Умение. № 1. С. 152-161.

Аиалог организационных культур в создании общеевропейского пространства высшего образования (2010) : Реализация принципов Болонского процесса в международных образовательных программах с участием России : моногр. / С. В. Ауков (рук.), Б. Н. Гайдин, В. А. Гневашева, К. Н. Кислицын, Э. К. Погорский. М. : Изд-во Моск. гуманит. ун-та. 260 с.

Ивойлова, И. (2015) Минобнауки выяснило, куда идут работать выпускники [Электронный ресурс]// Интернет-портал «Российской газеты». 23 июня. URL: http://www.rg.ru/2015/06/23/ vipuskniki-site.html [архивировано в WebCite] (дата обращения: 20.06.2017).

Ильинский, И. М. (2002) Образовательная революция. М. : Изд-во Моск. гуманит.-социальн. академии. 592 с.

Ильинский, И. М. (2016) Собрание сочинений : в 5 т. М. : Терра. Т. 1. Философия Происходящего. 672 с.

Ильинский, И. М., Ауков, В. А. (2005) Московский вуз глазами студентов: По материалам опроса студентов государственных и негосударственных вузов Москвы, март - апрель 2004 г. М. : Изд-во Моск. гуманит. ун-та. 64 с.

Каждый четвертый выпускник вуза в России не смог найти работу (2015) [Электронный ресурс] // Интерфакс. 16 октября. URL: http://www.interfax.ru/russia/473903 [архивировано в WebCite] (дата обращения: 20.06.2017).

Кузнецова, Т. Ф. (1990) Философия и проблема гуманитаризации образования. М. 117 с.

Кузнецова, Т. Ф. (2012) Культурная картина мира: теоретические проблемы : науч. монография. М. : ГИТР. 250 с.

Ауков, В. А., Гневашева, В. А. (2009) Человеческий потенциал студента - образовательный потенциал вуза : По материалам мониторинга «Российский вуз глазами студентов» (этапы 2004-2008 годов). М. : Изд-во Моск. гуманит. ун-та. 69 с.

Ауков, В. А., Аапшин, В. А. (2010) Человеческий потенциал и повседневность // Знание. Понимание. Умение. № 3. С. 211-215.

Ауков, В. А., Ауков, Вл. А. (2008) Тезаурусы : Субъектная организация гуманитарного знания. М. : Изд-во Нац. ин-та бизнеса. 784 с.

Ауков, В. А., Ауков, Вл. А. (2013) Тезаурусы II : Тезаурусный подход к пониманию человека и его мира : монография. М. : Изд-во Нац. ин-та бизнеса. 640 с.

Ауков, В. А., Ауков, Вл. А. (2014) Методология тезаурусного подхода: стратегия понимания // Знание. Понимание. Умение. № 1. С. 18-35.

Минобрнауки РФ: трудоустройство выпускников-инженеров составляет 100\% (2015) [Электронный ресурс] // РИА Новости. 8 октября. URL: http://ria.ru/society/20151008/1298734793. html [архивировано в WebCite] (дата обращения: 20.06.2017).

Плаксий, С. И. (2014) Высшее образование: вызовы и ответы : монография. М. : Нац. ин-т бизнеса. 604 с. 
Тихомиров, А. А. (2016) Инновационные образовательные технологии как способ повышения учебной мотивации студентов // Инновационные образовательные технологии в современном университете. М. : Изд-во РЭУ им. Г. В. Плеханова. С. 5-16.

Дата поступления: 15.07.2017 2.

Тихомиров Амитрий Андреевич - кандидат социологических наук, доцент кафедры политологии и социологии РЭУ им. Г. В. Плеханова. Адрес: 117997, Москва, Стремянный пер., 28, корп. 1. Тел.: +7 (495) 958-23-27. Эл. адрес: dat1983@yandex.ru

Сиднева Екатерина Владимировна - студент 4 курса кафедры политологии и социологии РЭУ им. Г. В. Плеханова. Адрес: 117997, Москва, Стремянный пер., 28, корп. 1. Тел.: +7 (495) 958-23-27.Эл. aдpec:k-sidneva95@mail.ru

Tikhomirov Dmitry Andreevich, Candidate of Sociology, Associate Professor, Department of Political Science and Sociology, Plekhanov Russian University of Economics. Postal address: Bldg. 1, 28 Stremyannyi Lane, 117997 Moscow, Russian Federation. Tel.: +7 (495) 958-23-27. E-mail: dat1983@yandex.ru

Sidneva Ekaterina Vladimirovna, 4th year student, Department of Political Science and Sociology, Plekhanov Russian University of Economics. Postal address: Bldg. 1, 28 Stremyannyi Lane, 117997 Moscow, Russian Federation. Tel.: +7 (495) 958-23-27. E-mail: k-sidneva95@mail.ru

\section{Аля циитирования:}

Тихомиров А. А., Сиднева Е В. Оценка выпускниками московских вузов социально-гуманитарного профиля своего образования и перспектив трудоустройства [Электронный ресурс] // Горизонты гуманитарного знания. 2017, №4. URL: http://journals. mosgu.ru/ggz/article/ view/582 (дата обращения: дА.мм.гггг). DOI: 10.17805/ggz.2017.4.7 